\title{
a praia
}

\section{Karina Gomes Barbosa}

A praia não é das mais bonitas. É espremida entre uma enorme coluna de areia que a circunda por trás. Uma encosta. Os banhistas se acotovelam no espaço exíguo em busca do sol que, complacente, concede o ar da graça para cada um e todos ali. Não é, definitivamente, a praia da temporada. Nem, tampouco, uma praia privê, dessas a que só comparecem caras conhecidas dos seguranças ou pulseiras de plástico personalizadas familiares aos mesmos e fabricadas com tamanha parcimônia que nunca deixariam o lugar lotado daquele modo.

Nos interessaremos pouco, neste instante e em instante qualquer destes escritos que compõem nosso tempo particular, meu e teu, caro leitor, pelas duzentas e trinta e sete pessoas que veraneiam inocente e impunemente na praia inominada. Sim, são somente duzentas e trinta e sete pessoas, o que pode parecer pouco diante dos números superlativos de uma praia como copacabana ou a riviera ou punta ou saint tropez, mas naquele espaço tão mínimo em que a enorme encosta resolveu ser generosa e se erodir e permitir que os banhistas vislumbrassem uma nesga de mar aberto, aberto mesmo, sem pedras, sem arrebentação e só com aquele horizonte tão enorme perdido à frente, e areia branca e límpida e se bronzeassem com urucum na década de oitenta, e bastou só uma escada de madeira, duzentas e trinta e sete pessoas era muito. 
Mas deixemos para lá essas pessoas que, nesta narrativa, serão apenas parte do cenário; comporão detalhes; servirão de pano de fundo para as ações sobre as quais nossos olhos e mentes irão se concentrar. Como já dissemos, faz sol. O dia é colorido por tons intensos, forte amarelo do sol, azul royal do céu rajado de nuvens branco-de-sabão-em-pó, peles dourado-brilhantes construídas à base de bronzeador, água salgada e fator de proteção 20, guarda-sóis vermelhos azuis alaranjados, e aquela areia limpa em tons pastéis.

(Era um milagre imaginar que as pouco mais de duzentas pessoas ali reunidas naquele dia, e todas as outras pessoas reunidas ali em dias anteriores àquele, desde que, muito tempo depois de a encosta se erodir, construíram a escadinha que descia àquele naco de praia, não sujassem a minúscula praia, e não levassem cachorros à praia, ou deixassem latas velhas, sacos vazios, papéis de picolé, tampinhas, sujeiras variadas).

A areia era limpa. Não havia cães. À parte isso, a praia era uma praia como outra qualquer. Nela reinavam risos, gritos infantis, conversas, músicas de sons portáteis, vento, a onda colorindo a areia de marrom, o branco do mar se convulsionando na beira da praia, a praia. Naquela ipanema particular, ainda que fosse absolutamente pública, não houvesse privatização do terreno, cobrança de entrada ou seguranças, havia mulheres de biquínis novos, corpos normais, biquínis velhos, corpos normais, biquínis da moda tremendamente caros, corpos esculpidos durante trezentos dias para que nos outros sessenta os biquínis da nova coleção da rosa chá pudessem se assentar corretamente, maiôs, corpos decaídos, maiôs, corpos tímidos, maiôs, corpos infantis ainda em formação, maiôs, corpos gordos, todos convivendo em harmonia na democracia que é a areia próxima ao mar. 
Ainda que todas as pessoas ali pudessem ver as estrias umas das outras, as cicatrizes da cirurgia de apendicite, o excesso de celulite junto aos culotes, a depilação mal feita junto à virilha, a marca deslocada das férias passadas com o biquíni antigo, havia uma mulher da qual pouco se podia ver. Ela estava sentada em uma roda ao fundo da praia, quase junto à encosta, mas não era por timidez, os amigos só haviam encontrado lugar ali. Cabelos castanhos, na altura dos ombros, lisos, sorriso de muitos dentes, franco, e nariz afinado. Usa uma pulseira preta, de pedrinhas em forma de bacilo, que recobre todo o pulso. Não tem brincos. Nem aliança. Nos olhos, cobertos por três camadas de rímel preto das quais os companheiros de praia não sabem, um par de óculos jackie o. de aro de tartaruga. A pele é clara, desbotada, ainda que passe longe do alvo. Não vê sol há tanto tempo que nem se preocupa com protetor solar. Há muito que dourar antes das preocupações com superexposição, câncer de pele e manchas de bronzeamento irregular. Precisa antes parecer banhada pelo sol, minimamente. Conversa, no momento exato em que é descrita, sobre música. Sobre, especificamente, como gosta do "levante oitentista produzido por certas cantoras destalentadas para se tornarem vanguarda novamente". O homem loiro e alto à frente dela obviamente não entende nenhuma das palavras quanto mais o significado delas, mas sabe que ela é uma espécie de sumidade em alguma área da música que ele, obviamente, não é, ele que não é especialmente sumidade em nada, então aquiesce rindo, naquele clima saudável de discussão praiana em que ninguém nunca sai vencido, antes recompensado com mais uma cerveja gelada. E então, depois da frase de efeito, a mesma que escreveu na página cento e dezoito da sua tese de doutorado por concluir nos próximos setenta e dois dias, ela olha o mar. E, como pressentindo a melancolia que viria carregando aquele olhar silencioso, os quatro amigos em volta dela na roda calaram. 
Ana pediu silenciosamente ao namorado para passar mais bronzeador em suas costas; o homem loiro bebeu mais gole da cerveja; Carla fingia que ria da brincadeira das crianças feias da família sulista ao lado.

Ela contemplava o mar.

E todos à sua volta compreendiam a solenidade daquele instante, assim como tinham certeza de que ela não os imporia uma tortura silenciosa que durasse mais que uma vaga. Ela suspirou e perguntou ao homem loiro: então, você agora só finge que é surfista?

Ele riu, a prancha quebrara, uma pena. Ela emendou veio bem a calhar, e um riso coletivo da piada dissipou o momento desconfortável de antes. E todos conversaram sobre quaisquer coisas leves, socialmente não embaraçosas e que nunca evocassem nenhum olhar embaciado para o mar novamente. Não naquele domingo, quando conseguiram a muito custo tirá-la de casa, da frente do computador, da tese de doutorado, das garrafas de cocacola, das bolachas recheadas, dos seriados de tevê, dos dias sem banho, da auto-comiseração. Levou uma semana de negociações a ida à praia, e ela provavelmente só aceitou porque era a ipanema particular deles, um lugar afastado, pouco movimentado, discreto, onde ela poderia continuar com as roupas que usava quando saía de casa, o que era bem raro atualmente. Teve de dormir cedo no sábado, o que era uma tortura, visto que seu cérebro produzia boas frases-de-efeito-para-teses-de-doutorado na madrugada do sábado para domingo enquanto a tevê gorgolejava os últimos programas nas costas dela, teve de escolher previamente uma roupa e experimentála. Tinha duas calças jeans iguais. Uma velha e uma muito velha. 
Escolheu a muito velha, sua preferida, mais apropriada à praia, a encher de areia ou eventuais passeios à beira da água. Escolheu uma camiseta cinza, com as palavras la mer em francês, um pequeno deleite, pensou em inglês, a private joke, enquanto colocava as peças no sofá e ia se deitar antes mesmo do fim da novela, porque saberia que, sem levar o cérebro à exaustão como todos os dias, não iria conseguir dormir tão cedo, nem tão facilmente, e iria se revirar por todos os lados que conseguisse, pensar em coisas, querer se levantar e digitar frases, idéias, trechos inteiros, beber cocacola, ir ao banheiro, roer as unhas, se jogar da janela do primeiro andar.

No dia seguinte, estava de pé às sete com sofreguidão. Mal conseguia descolar os olhos. O alarme tocou. Tinha meia hora para se mostrar apresentável antes de os amigos chegarem. Lavou o rosto, penteou os cabelos, sentou na cama, teve ímpetos de se deitar novamente, esfregou os olhos com força com os nós dos dedos, olhou para a janela com a cortina de linho branco, bem fina, o sol começando a ficar imponente lá fora, impaciência, suspirou. Começou a tirar a camisola amarelo-clara, ainda na cama, e arrastou-se até o sofá da sala para vestir o que havia escolhido na noite anterior. O telefone tocou, virou-se rapidamente para atender, sempre odiara o som do telefone tocando muito tempo, ademais não queria preocupar nenhum dos amigos, certamente era algum deles. Era Carla, queria certificar-se de que estava acordada, não precisa levar protetor, tenho um novo aqui, você prefere atum ou frango, me esqueci de perguntar ontem, levo cerveja também, pra evitar de comprar tudo lá, e água, mas não vou levar nenhuma cocacola, hoje não, ok, Carla riu dessa piadinha, mas ela permaneceu muda no fone, você está levando biquíni, passamos aí em vinte minutos, ok? Ela só respondeu às duas últimas perguntas. Não, ok. 
Claro que Carla deveria saber que ela não levaria biquíni, que pergunta sem sentido, Carla deveria saber àquela altura que ir à praia já era concessão o bastante. Por isso, quando a amiga desligou o telefone satisfeita com o ok quanto ao horário, ela ficou segurando o aparelho tentando encontrar nele explicação para o comportamento idiossincrático da outra.

Percebeu que estava de calcinhas, o telefone interrompeu a operação de trocar de roupas. Vestiu-se, procurou os óculos escuros na segunda gaveta da cômoda, a gaveta das coisas quebráveis, em que tudo era muito delicado e, portanto, guardado com muito zelo, ao contrário da primeira gaveta, onde ficavam as coisas que podiam ser retiradas e colocadas à revelia delas mesmas, inclusive em curtos espaços de tempo. Achou os óculos, colocou-os no rosto e foi ao espelho de trinta por trinta e cinco centímetros no banheiro para analisar a combinação lentes armação rosto. Considerou o resultado satisfatório e indicou isso ao espelho com um menear de sobrancelhas. Ao lado da pia do banheiro estavam os outros óculos, os que importavam e a ajudavam a se guiar em todos os momentos que não fossem os momentos diante da tela do computador - às vezes, dependendo do cansaço, inclusive neles. O primeiro impulso foi colocá-los na caixinha e depositá-los na bolsa de lona que levaria no convescote, mas resistiu. Não haveria nada que ver de perto e com detalhes, pensou. Escovou os dentes. Calçou o par de all star pretos, com as meias brancas. Tinha ainda dez minutos. Ligou a tevê. Não pensou em nada.

Me passa a água de coco, por favor? Ela pediu ao homem loiro e alto à frente, Diego. Diego passou a água de coco e roçou de leve a perna esquerda dela. Ela não conseguiu conter um suspiro. Ana parou de conversar com o namorado, João. Houve um momento de suspense na roda. 
O primeiro momento de suspense real desde que tinham chegado à praia, às nove horas, a viagem era longa, uma hora de carro em alta velocidade, com Diego dirigindo. Eles chegaram, a praia já relativamente cheia, só conseguiram uma barraca atrás, não foram olhados, pelo menos não por conta da mulher usando calças jeans, mas se foram, foi por causa do loiro alto que seguia na frente de todos. Ela sorriu, não foi nada. Não foi nada, insistiu, ante a cara de susto que ele ainda fazia, mão suspensa entre ela e a mesa, com a água de coco na mão. Relaxa, ela comandou e agarrou a água de coco com as duas mãos, puxando os dois canudinhos, azul vermelho, para perto de si. Ela se curvou para a frente na esteira de palha que ocupava, pernas cruzadas junto ao corpo, para beber logo toda a água de coco que o vendedor havia justo entregue. Adorava água de coco. $\mathrm{O}$ momento passou, não sem que Ana tivesse lançado um olhar de pavor a Carla, com medo de um escândalo, um desmaio, um grito, enfim, qualquer comportamento socialmente estranho. Ela, se viu, não repreendeu a amiga. Bebia a água de coco. Não pensava em nada.

Estava feliz.

Chegou a ouvir, enquanto apreciava o domingo ensolarado de olhos fechados, os olhos cravejados de rímel que ela passou nos dez minutos de interregno que teve entre a ligação telefônica, a observação muda e desatenta da tevê e o completo desespero, algumas notas de sua canção de jazz favorita, e fez com os lábios. i put a speel on you. Sem emitir som algum, sem deixar ninguém notar.

A felicidade durou dez minutos,

e dez minutos foram o bastante para ela por enquanto. 
De repente, o devaneio passou. Se tivesse cronometrado, coisa que não fez porque não costumava usar relógios e porque a fase de se compassar ao tempo com a batida dos pés havia passado há cerca de oito meses, pelo que se lembrava. Mas, ainda que sem um marcador de tempo, sentiu a melodia se esvair de uma vez, interrompida pelo som da agonia que, como um alarme, a fez se levantar da areia com dificuldade. Vou caminhar. E ao dizer isso observou o efeito cênico de suas palavras nas feições dos amigos. Precisa de companhia, vai aonde, cuidado, mas, como assim, foram as interrogações carregadas pelo vento que não mereceram resposta dela. Que disse apenas. Se eu demorar e vocês quiserem ir. Podem ir. Chamo um táxi.

Tchau.

Não deu tempo a que ninguém engatasse séries de indagações. Não era uma questão de dialogar. Era uma decisão unívoca, pensou gostando da palavra que surgiu. Virou as costas. Andou lentamente, mancando um pouco da perna direita, tão pouco que seria difícil perceber que mancava, até a escada que levava ao alto, ao mundo real distante da praia de mentira que se ocultava ali embaixo. Os tênis chutavam a areia, mas ela tomava cuidado para não sujar ninguém na praia, ainda que seguisse pelo caminho mais deserto do lugar apinhado. Fazia calor àquela hora. Mais calor do que poderia prever, mas isso não lhe trouxe arrependimento de ter vindo de calças. Nem por um segundo. Perto da escada, já, na encosta, virou a cabeça para observar um vendedor de chapéus de palha feios que carregava a mercadoria para o meio da multidão. Dali de onde ambos estavam, podia vê-lo sem a contaminação de cabeças, cabelos, outros pedaços de corpos, sombrinhas, barracas. Cinco chapéus em cima, cinco chapéus embaixo, em duas fileiras, de abas largas e sem adornos, pelo menos isso. 
Sorriu para si mesma a lembrar do próprio minimalismo excessivo.

Sacolejando em coreografia à medida que o vendedor, ele mesmo de bonés, ia enfiando os pés na areia com prática e ainda assim desajeitadamente subindo e descendo subindo e descendo subindo e descendo na areia fofa. Ela se divertia observando a pequena cena privada do vendedor antes de exibir ao público sua mercadoria. E talvez tenha sido o sol, talvez tenha sido o barulho hipnótico do mar, talvez tenha sido o efeito retardado do comprimido que tomara ontem à tarde, talvez tenha sido um laivo de imaginação, mas por alguns segundos os chapéus tomaram a forma de uma deliciosa alucinação praiana, e agora não apenas subiam e desciam, mas rodavam, ao sabor de um vento que não existia naquela intensidade, rodavam, os de cima no sentido horário, os de baixo no sentindo anti-horário, rodavam como fossem parte do cenário de um musical hollywoodiano do primeiro terço de século. Rodopiavam e de repente rodopiaram tão rápido que ela passou a pensar em outros filmes, outro gênero cinematográfico, não eram mais chapéus, eram as bolas de feno do abandono dos faroestes do cinema, eram as bolas de feno do desenho do picapau, e naquele instante, se tivesse olhado para o lado, qualquer lado, ela teria visto não mais a praia, mas o deserto cinematográfico, uma paisagem solitária, seca e avermelhada que inspirava violência. Ela, contudo, não olhou, fascinada que estava pela visão das bolas de feno rolando juntas, no mesmo compasso, pelo cenário duro da encosta. Não havia mais vendedor, havia o vento, havia o vento sentido no rosto e desejoso de levar-lhe os cabelos para uma outra direção, e, se apurasse os ouvidos, aquele silvo tão característico dos filmes, dá licença, alguém disse, e só então ela percebeu que bloqueava o acesso à escada. Moveu-se para o lado e tudo se fora. Vendedor, chapéus, o clima do deserto e todas as suas ilusões. Não sabia mais onde estavam os amigos. 
Pouco lhe importava. Queria a solidão, eles haveriam de entender que a ida à praia não cura aquele desejo insano pela solidão.

Subiu os degraus e foi se esconder no imenso espaço aberto à sua frente. Andou no sol, por muito tempo, mãos nos bolsos, em linha quase reta se alguém resolvesse traçar uma linha com régua nos passos dela, chutando a areia aqui e acolá enquanto andava e se escondia cada vez mais na inexistência de pessoas à sua volta. $\mathrm{O}$ sol resolveu ir embora, aos poucos, e aos poucos com a despedida do sol despediamse as pessoas lá na praia, já longe dela, cada passo que ela dava era alguém indo embora, se despedindo dos amigos, subindo os degraus, ligando o carro, tentando não sujar tudo de areia, cada inspiração do corpo dela era uma toalha sendo dobrada, um baldinho sendo guardado, uma camiseta sacudida, um cabelo preso, tênis calçados, uma parte de cima do biquíni sendo retirada para dar mais conforto. Cada segundo de mergulho dela na solidão era um movimento de partida das pessoas lá embaixo, mas as pessoas lá embaixo não nos interessam. A cena de todo o palco incrustado lá embaixo se desfazendo em bastidores não importa nada. Importa apenas sabermos que agora ela estava sozinha, completa e absolutamente sozinha, após a partida das crianças, das mães, das mulheres solteiras, dos homens magros e dos gordos, dos trabalhadores e dos visitantes, das crianças com queijo coalho, dos vendedores de protetor solar, do homem com os chapéus hollywoodianos, dos seguranças, dos guardadores de carro, dos ambulantes de bebidas, dos amigos, dos desconhecidos, dos desimportantes. Durante todo o tempo em que o sol ia se escondendo aos poucos onde quer que fosse aquele lugar secreto e inacessível que deixava espaço para a noite, ela ficou parada, numa ponta distante da encosta, frente ao mar e a algumas pedras muito embaixo, seria uma grande queda. 
Ela permaneceu ali, os cabelos tentando ir mas querendo ficar junto dela em desalinho, os braços protegidos pelas mãos que os agarravam, as pernas abertas imóveis, os olhos pintados de rímel escondidos debaixo dos óculos escuros. Ninguém saberia dizer se ela manteve os olhos abertos, se fitava o mar ou se despedia do sol. Ela era como uma geleira resistindo ao calor. Os braços estavam arrepiados. O maxilar duro, os lábios crispados, a expressão imóvel. Por dentro, poderia tremer que ninguém saberia jamais. Poderia ter o coração apertando e ao mesmo tempo dilacerando todos os músculos em volta que ninguém saberia. $\bigcirc$ que ela sabia, contudo, mais que nunca, talvez iluminada pela força opressiva do por do sol, é que viver era muito, muito perigoso, como clarice já dissera, e ela nem precisava perguntar, como perguntou beatriz. Ser feliz era ainda mais perigoso. Ela sabia disso há muito tempo, desde a vez única e ínfima em que tentou ser feliz. Em que tentou sorrir e se entregar às ondas.

Era hora de voltar. Ainda havia luz, e já era escuridão. Desceu lentamente as escadas, como se tentasse adiar aquele momento inevitável e definitivo pelo qual esperou o dia todo. Como um cúmplice daquele segredo, o sol teimava em deixar uma réstia de resistência à noite, como se o próprio dia tivesse esperado, todo ele, aquele momento, para só depois se despedir. Prometia ser um espetáculo sem platéia, o momento pelo qual estavam a praia, as pedras e a areia esperando. Os solados dos tênis tocaram a areia. Tirou-os com os pés, abaixou-se com certa dificuldade para tirar as meias. Andou alguns passos com os pés sentindo a areia, deixando os pés afundar na superfície fofa e limpa, tudo era feito numa grande cena em slowmotion dum filme qualquer. Parou em frente ao mar, o último suspiro das ondas tocando-lhe os pés. Desabotoou a calça, tirou a blusa. Escondia um biquíni por baixo da roupa, todo aquele tempo, para a contemplação da praia, do sol que ia, do mar. 
Vista de longe, num contraluz, era um belo corpo de mulher, longilíneo, com curvas bem desenhadas e proporcionais, pernas firmes, seios dispostos. E se o sol fosse uma câmera que pudesse aos poucos, a um só tempo, iluminar aproximando-se, ou aproximar-se iluminando, veríamos num close a coisa mais importante que se escondeu de todos não apenas naquele domingo, mas muitos dias antes. A cada curva existente do corpo dela correspondiam linhas, marcas, rasgos profundos numa pele para sempre marcada pelas cicatrizes dum acidente qualquer. Era como se o corpo dela fosse uma grande linha que um quiromante, ao ver, prenunciaria um destino trágico. Diz quantos desastres tem na minha mão. Cada naco de carne visível deixado pelas ausências do biquíni abrigava sulcos ainda avermelhados, ainda doloridos, alguns abertos, sem sangue, mas pulsando a carne e a dor para o mundo, o vento a contribuir com a tortura carregando areia para todas as cavidades expostas, para todas as cirurgias malsucedidas, para a impossibilidade de ir para a cama, para a inexistência da intimidade compartilhada, para a eterna vergonha de exibir as pernas de carnes deformadas nas coxas pelas amarrações que tiveram de ser feitas e, como pústulas, haviam estourado e estavam expostas. Era como se todas as marcas estivessem esperando aquele domingo para exibirem o segredo de carne que guardaram bem por certo tempo, como se exigissem atenção depois de serem vilmente escondidas. Ela ficou parada, exibindo o espetáculo grotesco solitário para o mar, dando suspiros de quando em quando, que aumentavam quando o vento aumentava, um termômetro ainda pequeno da dor. $\mathrm{O}$ sol, satisfeito com o prólogo, foi. Era noite. Era hora de tirar os óculos e exibir os olhos borrados pelo rímel que escorreu, não conseguiu nem tentou, na verdade, evitar o choro, depois de tanto tempo sem sair, pensou de repente, enquanto atirava os óculos no chão e percebia que novas lágrimas ajudavam a criar um novo caminho das lágrimas em direção aos lábios, que era, com todas aquelas seqüelas dum dia qualquer, uma grande polissemia, ela mesma, uma variedade de coisas, 
tristezas e sofrimentos,

mas não demorou muito tempo com pena, lembrou-se apenas do professor que tanto gostava daquela palavra, polissemia, e num instante já havia esquecido a autopiedade, o professor, a dor que as carnes abertas, tão poucas gorduras ela tão magra, the proporcionavam. Deu mais um passo. $O$ mar chegou perto da canela, chegou perto da primeira marca na perna direita, um rasgo que iniciava na canela e abria caminho pelo meio da perna, ladeando o joelho, e expondo toda a gordura daquela coxa que um dia já fora firme de esporte e cuidados com o corpo. Foi aquela a primeira marca a sentir o gosto do sal. Depois outra, e mais outra, e mais outra, e mais outra, e subitamente ela pensou por que estava de biquíni, os peitos não eram mais feios que todo o resto, retalhados, dilacerados, dois montes disformes de carne seguros apenas pelo formato do sutiã, deu mais um passo dentro da água e foi o abdome que sentiu o gosto do mar, salgado, escorreram lágrimas de fúria dos olhos dela, a dor era tamanha, deu outro passo, e os peitos protegidos pelo biquíni doeram muito ainda assim, e enquanto the agrediam por fora o sal e a água começavam a entrar no corpo dela, abriu a boca, engoliu uma duas três quatro vezes cambaleou de tontura pela dor a água estava na altura do pescoço o rosto fora deixado intacto não sentia dor mas os olhos teimavam em chorar mesmo assim os olhos pretos do rímel escorrido um toque a mais de dramaticidade mais um passo e a dor aumentando o ventre se abriu e o sangue subiu lentamente para a superfície mais um passo a água na altura do nariz inspirou longamente e sentiu os pulmões cheios de água e sal. Fechou os olhos. Já não chorava. A água do mar carregou o rastro de lágrimas e limpou o rosto dela. Se houvesse luz seria possível ver-lhe as carnes abertas por todo o corpo ainda vivo boiando braços abertos mas inconsciente pela dor vários pedaços de pele carne e gordura pequenas ondas movimentando-o para cima para baixo uma imensa tristeza que se esvaía junto com o resto de vida. 
A noite testemunhou a respiração ir deixando aos poucos de ser, inspira respira inspira respira inspira inspira, ela engasgou uma última vez, sem ter forças já para tossir, sem ter a consciência da necessidade da tosse. Foi arrastada pelas ondas, os braços abertos, as carnes das coxas e do ventre balançando pelas ondas, voltou aos poucos do mar até ser depositada sem carinho pelas ondas na margem. Tudo demorou muito. Do alto da praia, lá em cima, a noite observava tudo, pacificada. Dali a pouco, amanheceria. 